\title{
Disleksisi Olan Çocuklarda Görsel Algı Becerilerinin, Okuma Becerileri Üzerine Etkisinin Incelenmesi
}

Investigation of The Effects of Visual Perception Skills on Reading Skills in Children with Dyslexia

Büşra KARAKAYA', ONUR ALTUNTAŞ²

${ }^{1}$ Ergoterapist, Kartal Dr. Lütfi Kırdar eğitim ve Araştırma Hastanesi Adatepe Toplum ve Ruh Sağlığı Merkezi, İstanbul.

2 Yrd.Doç., Hacettepe Üniversitesi Sağlık Bilimleri Fakültesi Ergoterapi Bölümü, Ankara.

\section{öz}

Amaç: Disleksisi olan çocuklarda görsel algı becerilerini geliştirmeye yönelik müdahalenin, okuma becerileri üzerine etkisini belirlemektir. Gereç ve yöntem: Çalışmaya disleksi tanısı almış 9 ve 14 yaşlarında iki çocuk dahil edilmiştir. Görsel algı becerilerinin değerlendirilmesi için; Motor Yetenek Olmaksızın Görsel Algılama Testi-3 (MVPT-3), okuma becerilerinin değerlendirilmesi için; Sesli Okuma Becerisi ve Okuduğunu Anlama Testi (SOBAT-2) kullanılmıştır. Değerlendirmeler sonrasında her bir çocuğa 8 hafta boyunca haftada 1 seans( $45 \mathrm{dk}$ ), görsel algı becerilerini geliştirmeye yönelik kişi merkezli Ergoterapi müdahalesi uygulanmıştır. 8 hafta sonunda değerlendirme testleri tekrar uygulanmış ve müdahalenin etkinliği incelenmiştir. Sonuçlar: Çalışmamız sonucunda her iki çocukta da hem görsel algı becerileri değerlendirmesinde, hem de akıcı okuma ve okuduğunu anlama becerileri değerlendirmesinde performans artışı tespit edilmiştir. Tartışma: Çalışmamızda disleksi tanısı almış çocuklarda görsel algı becerilerini geliştirmeye yönelik uygulanan kişi merkezli ergoterapi müdahalesinin, akıcı okuma ve okuduğunu anlama becerilerini artırmaya olumlu yönde etki ettiği tespit edilmiştir. bu kapsamda konuyla ilgili yapılacak olan çalışmaların daha fazla örneklemin yer aldığı geniş katılımlı gruplarla, daha uzun süreli uygulanması şeklinde planlanmasıyla, bunun yanı sıra aile bireyleri ve eğitimcilerin disleksi hakkında bilinçlendirilmesi ile daha iyi sonuçlar elde edileceği düşünülmektedir.

Anahtar kelimelere: Disleksi; Görsel algı; Ergoterapi

\section{A B S TR ACT}

Purpose: To determine the effects of the intervention for improving visual perception skills of children with dyslexia on their reading skills. Materials and Method: Two children, aged 9 and 14 years, who have been diagnosed with dyslexia have been included to the study. To evaluate visual perception skills: Motor-Free Visual Perception Test-3 (MVPT-3); for evaluation of reading skills: Oral Reading Skills and Reading Comprehension Test (SOBAT-2) has been used. After the assessments, to improvetheir visual perception skills, each child has been intervened with 
a person-centered ergotherapy for 1 session (45 minutes) per week for 8 weeks. At the end of the 8 weeks, the evaluation tests have been reapplied and the effectiveness of the intervention has been examined. Results: As a result of our study, it is determined that there is performance enhancement in both children regarding not only visual perception evaluation skills, but also fluent reading and reading comprehension skills. Conclusion: In our study, it is determined that person centered ergotherapy intervention to improve visual perception skills in children with dyslexia affects fluency reading and reading comprehension skills positively. Within that scope, it is considered that the relevant studies which will be done will give better outcomes by implementing them to broad participation groups which have more samples for longer periods, and as well as, by raising awareness of family members and educators about dyslexia.

Key words: Dyslexia; Visual perception; Occupational therapy

i k olarak 1896 yılında Hinshelwood tarafından kullanılan disleksi kavramı ancak 1968 yılında Dallas'ta gerçekleştirilen Dünya Nörologlar Konferansı'nda kabul edilmiştir. Bu konferansta disleksi, "Normal zekâ düzeyine sahip bireyde yaşanan okuma güçlüğü" olarak tanımlanmıştır (Jaklewicz, 1997). Günümüzde kabul gören tanımıyla disleksi; normal ya da normalin üzerinde zekâya sahip, belirgin bir beyin patolojisi olmayan, dinleme, konuşma, okuma, yazma, akıl yürütme ile matematik becerilerinin kazanılması ve kullanılmasında önemli güçlükleri olan, ikincil olarak kendini idare, sosyal algılama ve etkileşim sorunları yaşayan, standart eğitime rağmen yaşına ve zekâsına uygun başarı gösteremeyen bireyler için tanımlanmış nörolojik kökenli gelişimsel bir bozukluktur (Aslan,2015).

Disleksinin yaygınlığı çeşitli toplumlarda farklılık göstermektedir. Amerika Birleşik Devletleri Eğitim Bakanlığı'na göre okula giden çocukların \%5-15'inde özel öğrenme güçlüğü görülmektedir. 28 ülkeden alınan verilere göre okuma bozukluğu (disleksi) Japonya ve Çin'de \%1 ile en düşük, \%33 ile Venezüela'da en yüksek oranda görülmektedir. A.B.D. de \%20 ve daha çok oranda çocuk okumayı öğrenme becerisinde zorluk çekmektedir (Doğan, 2012).

Disleksi tanısı almış olan çocuklarda görsel algı alanlarında bozukluklardan söz edilmektedir (Rodrigues ve ark., 2017). Duyu organları ile alınan işlenmemiş haldeki uyaranlar ilk aşamada bilginin kaynağını oluşturmaktadır. Bu uyaranlar nöronlar aracılığı ile beyne ulaşmakta ve girdilerin alınması beyinde gerçekleşmektedir. Disleksi tanı- sı olan çocuklarda bu uyaranların algılanmasında problem görülmektedir (Karatepe,2007). Problem alanı olan bu bozukluklar görsel algı süreçleri kapsamında; görsel-uzaysal algı, görsel ayırt etme, görsel bellek, görsel nesneleri yorumlama gibi pek çok alanı ifade etmektedir. Görsel algı becerilerini geliştirmeye yönelik yapılan çalışmalar, çocukların bu alanlarda daha başarılı performans sergilemesine katkı sağlamaktadır (Teleb, Mohamed, Elbert, 2016). Bireylerin görsel algı bozukluklarında değerlendirme ve müdahalesi ergoterapi rehabilitasyon süreci çerçevesinde yer almaktadır (Cooke, McKenna, Fleming, 2005). Bu kapsamda ergoterapi okuma güçlüğü yaşayan çocuklarla görsel-algısal becerilerinin geliştirmesi yönünde çalışmaktadır (Grajo, Candler, 2014).

Disleksi tanısı almış ve tanı almamış bireyleri içeren iki farklı grup ile yapılan bir çalışmada her iki grubun görsel algı becerileri ve okuma becerileri değerlendirilmiş, sonrasında bu iki grubun verileri karşılaştırılmıştır. Yapılan bu çalışmada görsel dikkat ve görsel algı süreçleri bileşenlerinin okuma becerileri ile ilişkili olduğu, disleksi tanılı okuyucularda görsel algı becerilerinin etkilenmiş olduğu sonucuna ulaşılmıştır (Jones, Branigan, Kelly, 2008).

Yapılan araştırmalarda görsel algı becerilerini geliştirmeye yönelik müdahale uygulanarak okuma becerilerindeki değişimi öngören bir çaIışmaya rastlanmamıştır. Bu araştırmalar doğrultusunda disleksi tanısı almış bireylerde görsel algı becerisini geliştirmeye yönelik Ergoterapi müdahalesinin okuma becerileri üzerindeki etkisini belirlemek amacıyla bu çalışma planlanmıştır. 


\section{GEREÇ VE YÖNTEM}

Çalışmamıza Hacettepe Üniversitesi Ergoterapi bölümü duyu bütünlüğü ünitesinde tedavi olan, yaşları 9-14 arası olan disleksi tanısı almış 5 çocuk dahil edildi. Çalışma öncesinde ailelere çalışma hakkında bilgi verildi ve çalışmaya katılmayı kabul ettiklerine dair onam formu imzalatıldı. Çocuklardan üçünün tedavi programına düzenli olarak katılamaması nedeniyle çalışmamız 9 ve 14 yaşlarındaki 2 çocuk ile tamamlandı. Çalışma kapsamında her bir çocuk için, 8 hafta boyunca, haftada 1 seans (45 dakika) olmak üzere görsel algı becerilerini geliştirmeye yönelik kişi merkezli ergoterapi müdahalesi uygulandı.

Çalışmamızda, görsel algı becerilerinin değerlendirilmesi için Motor Yetenek Olmaksızın Görsel Algılama Testi-3, okuma becerilerinin değerlendirilmesi için de Sesli Okuma Becerisi ve Okuduğunu Anlama Testi kullanılmıştır.

Motor Yetenek Olmaksızın Görsel Algılama Testi-3 (MVPT-3): Görsel algılama yeteneğini motor becerilerden bağımsız olarak değerlendiren, 4-100 yaş aralığında kullanılabilen testtir. MVPT3, özellikle öğrenme, motor veya kognitif bozuklukları olan bireylerde kullanılabilmektedir. Test; görsel algılamayı uzaysal ilişki, görsel ayrım, şekilzemin algısı, görsel tamamlama ve görsel hafıza olmak üzere 5 alanda değerlendirmektedir. Testte görsel hafıza ve görsel tamamlama alanları ikişer bölümde değerlendirilmektedir. Görsel hafıza 1 ve görsel tamamlama 1 bölümleri daha basit düzeyde iken, görsel hafıza 2 ve görsel tamamlama 2 bölümleri daha karmaşık şekillerden oluşmaktadır.

MVPT-3, 65 maddeden oluşur. Her madde, içinde tek bir doğru cevap bulunan 4 farklı seçenek içermektedir. Bireylerin seçtiği cevap puanlama tablosuna yazılarak ve doğru cevap "1", yanlış cevap " 0 " puan olarak hesaplanmaktadır. Görsel hafıza 1 bölümü (14-21. sorular) için 0-8, görsel tamamlama 1 bölümü (22-34. sorular) için $0-13$, görsel ayrım bölümü (35-45. sorular) için 0-11, uzaysal ilişki bölümü (46-50. sorular), şekil-zemin algısı bölümü (51-55. sorular), görsel tamamlama 2 bölümü (56-60. sorular) ve görsel hafıza 2 bölümü (61-65.sorular) için $0-5$ arası puan alınabilmektedir. 65 sorudan yanlış yapılan soru sayısı çıkarılarak bireyin aldığı toplam puan hesaplanmaktadır (Colarusso, Hammill, 2003; McCane,2006).
Sesli Okuma Becerisi ve Okuduğunu Anlama Testi-2 (SOBAT-2) : Özel öğrenme güçlüğü olan çocukların okuma ve okuduğunu anlama becerilerini ölçmeye yönelik bir değerlendirme testidir. 7-14 yaş aralığını kapsayan test, zorluk dereceleri aynı olup birbiri yerine kullanılabilecek paralel iki testten oluşmaktadır. Bu sayede yapılan çalışmada bu iki test ön test-son test olarak kullanılabilmektedir. Her testte çeşitli seviyelerde hazırlanmış özgün metinler ve bu metinlere ait okuduğunu anlama soruları bulunmaktadır.

Testte zorluk seviyesi gittikçe artan 13 metin, süre tutularak çocuğa sesli bir şekilde okutulmakta, bu esnada hatalı okumaları kayıt edilmekte ve metin sonunda çocuğa her bir metinle ilgili 5 soru yöneltilmektedir. Bu sayede test ile sesli okuma hızı, doğru okuma ve okuduğunu anlama parametreleri değerlendirilmektedir.

Yapılan değerlendirmede, bireyin okuduğu süre ve doğru okuduğu kelime sayısından aldığı puan; akıcı okuma puanını, sorulara verdiği yanıtIardan aldığı puan ise okuduğunu anlama puanını oluşturmaktadır (Özkök-Kayhan, 2011; Melekoğlu, Çakıroğlu, Erden ve ark., 2014).

\section{MÜDAHALE PLANI}

Ergoterapi müdahale programında görsel hafıza, şekil-zemin algısı, görsel ayrım, görsel tamamlama, uzaysal algı parametrelerini geliştirmeye yönelik müdahaleler uygulanarak bireyin görsel algı becerilerini artırmak hedeflenmiştir.

Müdahale programı; bireyin aktivite tercihleri ve değerlendirme sonuçları göz önüne alınarak hazırlanmıştır. Müdahale yöntemi olarak görsel algı beceri parametrelerini geliştirmeyi temel alan kişi merkezli aktiviteler tercih edilmiştir.

\section{OLGU1: B.A.K}

On dört yaşında olan erkek hastamız B.A.K. okula başladığı dönemde öğretmeni tarafından dikkat dağınıklığı şikayeti sebebiyle aile tarafından Dışkapı Hastanesi'nde Psikiyatri Bölümü'ne götürülmüştür. Sonrasında İbn-i Sina Tıp Fakültesi'nde 'özgül öğrenme güçlüğü tanısı' almıştır. Şu an Çankaya Özel Eğitim Merkezi'nde eğitim almaktadır. Aynı zamanda Sibel İsmet Çatık Ortaokulu'nda 8. sınıfta okumaktadır. Ailenin temel şikayeti B.A.K.' nın akademik becerilerde yetersizliği olduğu yönündedir. Birey aile ile iletişimde ve akran 
ilişkilerinde bir problem yaşamamakta ancak vaktinin büyük çoğunluğunu sanal ortamda oyunlar ile geçirmektedir. Özellikle masa başı aktivitelerde (ders çalışma, kitap okuma, puzzle yapma) dikkat ve konsantrasyon konusunda problem yaşadığını ifade etmektedir.

Aktivite tercihleri sanal ortam oyunları (bilgisayar, telefon oyunları) ve spor içerikli aktivitelerdir. Seanslar içerisinde sosyal iletişimi çok iyi sağlamakta ve motivasyonunu yüksek tutmaktadır. Seanslar esnasında bireyin keyif aldığı aktiviteler tercih edilirken, motivasyonu artırmak amacıyla süre ile yarışma ya da terapist ile rekabet şeklinde aktiviteler planlanmıştır.

Yapılan görsel algı becerileri değerlendirmesinde bireyin; görsel hafıza, görsel tamamlama, görsel ayrım, uzaysal ilişki, şekil-zemin algısı alanlarının her birinde problem yaşadığı sonucuna ulaşılmıştır. Bireyin aktivite tercihleri, yaş ve cinsiyet özellikleri göz önünde bulundurularak, problem saptanan alanlara yönelik kişi merkezli ergoterapi müdahalesi uygulanmıştır.

Tüm bunlar kapsamında görsel algı becerileri içeren aktiviteler haftalara ayrılarak planlan- mıştır. Müdahale planı yaparken kişisel özellikler, problem alanları göz önünde bulundurulmuş olup, aktivite dağılımı her hafta görsel algı parametrelerinin (görsel tamamlama, görsel hafıza, uzaysal algı, şekil-zemin algısı, görsel tamamlama) her birini içerecek şekilde belirlenmiştir (Tablo 1).

Müdahale sonucunda görsel algı becerileri ve okuma becerileri tekrar değerlendirilmiş ve sonuçlar bu şekilde ortaya çıkarılmıştır. Elde edilen sonuçlara göre kişi merkezli ergoterapi müdahalesi kapsamında olgu 1'in görsel hafıza, görsel tamamlama, görsel ayrım, uzaysal algı, şekil-zemin algısı parametrelerinin her birindeki performans puanında artış, aynı zamanda okuma becerilerindeki akıcı okuma ve okuduğunu anlama performans puanlarında da artış saptanmıştır (Tablo 2).

\section{OLGU 2: B.E}

Dokuz yaşında olan erkek hastamız B.E. ilkokula başladığında okuma becerisinin gecikmesi şikâyetiyle hastaneye başvurmuş ve Ankara Üniversitesi Tıp Fakültesi'nde 'özgün öğrenme güçlüğü' tanısı konulmuştur. Şu an Huzur Özel Eğitim

Tablo 1: Olgu 1'in Müdahale Programı

\begin{tabular}{|c|c|}
\hline 1. Hafta & $\begin{array}{c}\text { Top havuzundan nesne bulma, UNO kartları ile eş bulma hafıza oyunu, dart oyunu } \\
\text { aktiviteleri }\end{array}$ \\
\hline 2. Hafta & $\begin{array}{l}\text { Piano tiles (sanal oyun), kum torbasında hedef vurma, eşleştirmeli hafıza oyunu, } \\
\text { kelime avı bulmaca aktiviteleri }\end{array}$ \\
\hline 3. Hafta & $\begin{array}{l}\text { Basketbol, aklında tut oyunu (farklı desenlerdeki } 4 \text { kartı } 15 \text { saniyede hafızaya alıp } \\
\text { başka bir alanda aynısını dizme), sayı avı bulmaca aktiviteleri }\end{array}$ \\
\hline 4.Hafta & Bowling oyunu, Make\&Break oyunu aktiviteleri \\
\hline 5. Hafta & $\begin{array}{l}\text { Dikkat oyunu( farklı renk ve rakamlar içeren kartlar terapist tarafından hızlı bir } \\
\text { şekilde dizilirken istenilen renkteki rakamları toplama), masa tenisi aktiviteleri }\end{array}$ \\
\hline 6. Hafta & Geometrik şekilleri ayırt etme, Kinect (sanal gerçeklikte engelli koşu oyunu) \\
\hline 7.Hafta & Bul karayı-al parayı oyunu, Sudoku çözme, yapışkanlı tenis topu oyunu aktiviteleri \\
\hline 8. Hafta & Resimli fark bulma oyunu, Langırt oyunu, bilyelerle hedef vurma oyunu aktiviteleri \\
\hline
\end{tabular}


Tablo 2: Olgu 1'in 1. ve 2. Değerlendirme Sonuçları

\begin{tabular}{|c|c|c|}
\hline OLGU: B.A.K & 1. Değerlendirme & 2.Değerlendirme \\
\hline \multicolumn{3}{|l|}{ MVPT-3 } \\
\hline 1-Görsel Hafıza(1) & $8 / 8$ & $8 / 8$ \\
\hline 2-Görsel Tamamlama(1) & $6 / 13$ & $12 / 13$ \\
\hline 3-Görsel Ayrım & $9 / 11$ & $10 / 11$ \\
\hline 4-Görsel Uzaysal İlişki & $3 / 5$ & $4 / 5$ \\
\hline 5-Şekil-Zemin Algısı & $3 / 5$ & $4 / 5$ \\
\hline 6-Görsel Tamamlama(2) & $2 / 5$ & $4 / 5$ \\
\hline 7-Görsel Hafıza(2) & $2 / 5$ & $4 / 5$ \\
\hline \multicolumn{3}{|c|}{$\begin{array}{c}\text { Sesli Okuma Becerisi ve Okuduğunu Anlama } \\
\text { Testi-2 }\end{array}$} \\
\hline 1-Okuma Hızı Puanı & 58 & 58 \\
\hline 2-Doğru Okuma Puanı & 48 & 53 \\
\hline 3-Akıcı Okuma Puanı & 106 & 111 \\
\hline 4-Okuduğunu Anlama Puanı & 51 & 54 \\
\hline
\end{tabular}

Merkezi'nde eğitim almakta, aynı zamanda Çankaya ilkokulu'nda 3. sınıfta okumaktadır. B.E. ile ilgili olarak ailenin temel şikâyetlerinin çok fazla sakarlık sebebiyle kendisine ve çevresine zarar vermesi, akademik becerilerde yetersiz olması ve dikkatinin dağınık olması olduğu tespit edilmiştir.

Bireyin aktivite tercihlerinin futbol oyunları, hareket ve rekabet içerikli oyunlar ve boyama aktivitesi olduğu tespit edilmiştir. Birey iletişim ve sosyal etkileşimde problem yaşamamakta ancak yenilgiye toleransının düşük olduğu, bu sebeple kurallı oyun oynamakta zorlandığı ancak rekabet içerikli aktivitelerde daha yüksek motivasyon sağladığı ve aktiviteye odaklanabildiği saptanmıştır. Kişisel özellikleri göz önüne alınarak bireyin görsel algı becerilerini geliştirmeyi hedefleyen aktiviteler genellikle hareketli oyunlardan seçilmiş, böylece seanslara aktif katılımı sağlanmıştır.
Yapılan görsel algı becerileri değerlendirmesinde bireyin; görsel hafıza, görsel tamamlama, görsel ayrım, uzaysal ilişki, şekil-zemin algısı alanlarının her birinde problem yaşadığı sonucuna ulaşılmıştır. Bireyin aktivite tercihleri, yaş ve cinsiyet özellikleri göz önünde bulundurularak, problem saptanan alanlara yönelik kişi merkezli ergoterapi müdahalesi uygulanmıştır.

Tüm bunlar kapsamında görsel algı becerileri içeren aktiviteler haftalara ayrılarak planlanmıştır. Müdahale planı yaparken olgu 2'nin kişisel özellikleri, problem alanları göz önünde bulundurulmuş olup, aktivite dağııımı her hafta görsel algı parametrelerinin (görsel tamamlama, görsel hafıza, uzaysal algı, şekil-zemin algısı, görsel tamamlama) her birini içerecek şekilde belirlenmiştir (Tablo 3). 
Tablo 3: Olgu 2'nin Müdahale Programı

\begin{tabular}{|c|c|}
\hline 1. Hafta & Labirent bulmaca,hafıza kartları ile eş bulma oyunu, basket atma aktiviteleri \\
\hline 2. Hafta & $\begin{array}{c}\text { Renkli desen kopya etme taklit etme, taktil tahtaları ile aynısını diz oyunu (15 } \\
\text { saniye süreyle hafızaya alıp bakmadan dizme), kaleye şut çekme oyunu, resimli } \\
\text { fark bulma oyunu aktiviteleri }\end{array}$ \\
\hline 3. Hafta & $\begin{array}{c}\text { Toplarla duvardaki ışıkları vurma oyunu (aynı renkteki toplarla aynı renkteki } \\
\text { ışıkları vurma), yapışkanlı tenis topu oyunu aktiviteleri }\end{array}$ \\
\hline 4. Hafta & $\begin{array}{c}\text { Futbol topu ile hedefteki lobutu devirme oyunu, Twister oyunu, UNO kartları ile } \\
\text { hafıza oyunu aktiviteleri }\end{array}$ \\
\hline 5. Hafta & $\begin{array}{l}\text { Dart oyunu, üç boyutlu hafıza oyunu( kartta gösterilen şekli aklında tutup, } \\
\text { bakmadan } 3 \text { boyuta taşıma, tünelden top geçirme oyunu aktiviteleri }\end{array}$ \\
\hline 6. Hafta & Bul karayı-al parayı oyunu, sözcük avı bulmaca, hedefe şut çekme aktiviteleri \\
\hline 7. Hafta & $\begin{array}{c}\text { Labirent platformda bilye yuvarlama oyunu, penaltı çekme oyunu, aynı } \\
\text { geometrik şekilleri aynı renge boyama aktiviteleri }\end{array}$ \\
\hline 8. Hafta & $\begin{array}{c}\text { Mandala boyama aktivitesi, hareketli platformdan tünele basket atma } \\
\text { aktivitesi, engelli koşu aktivitesi }\end{array}$ \\
\hline
\end{tabular}

Müdahale sonucunda görsel algı becerileri ve okuma becerileri tekrar değerlendirilmiş ve sonuçlar bu şekilde ortaya çıkarılmıştır. Elde edilen sonuçlara göre kişi merkezli ergoterapi müdahalesi kapsamında bireyin görsel hafıza, görsel tamamlama, görsel ayrım, uzaysal algı, şekil-zemin algısı parametrelerinin her birindeki performans puanında artış, aynı zamanda okuma becerilerindeki akıcı okuma ve okuduğunu anlama performans puanlarında da artış saptanmıştır (Tablo 4).

\section{TARTIŞMA}

Disleksi tanısı almış olan çocuklarda görsel algıyı geliştirmeye yönelik müdahalenin, okuma becerileri üzerindeki etkisini belirlemek amacıyla yapılan çalışmamızda kişi merkezli ergoterapi müdahalesi dahilinde uygulanan görsel algı becerilerini geliştirmeye yönelik müdahalenin akıcı okuma ve okuduğunu anlama becerilerini artırmaya olumlu yönde etki ettiği tespit edilmiştir.

Özat tarafından 2010 yılında yapılan çalışmada öğrenme güçlüğü yaşayan çocuklarda, Frostig Görsel Algı Eğitim Programının görsel algı becerileri üzerine etkisi incelenmesi amaçlanmış, bu doğrultuda disleksi tanısı almış çocuklardan oluşan, kontrol grubu ve deney grubu olmak üzere iki grup ile çalışılmıştır. Çalışma sonucunda görsel algı eğitimi verilen bireylerde, görsel algı parametrelerinde artış tespit edilmiştir. (Özat,2010).
Çalışmamızda da literatür ile uyumlu olarak, uygulanan görsel algı becerilerini geliştirmeye yönelik kişi merkezli Ergoterapi müdahalesi sonucunda Olgu 1 ve Olgu 2 profillerinde görsel algı parametrelerinin her birinde performans artışı görülmektedir.

Jones ve arkadaşları tarafından disleksi tanısı almış bireylerde görsel algı bozukluğunun niteliği ve okuma becerileri ile ilgisini araştırmak için yapılan çalışmada, disleksi tanısı almış olan ve tanı almış olmayan iki grup bireyde görsel algı becerileri ve doğru okuma ile okuma hızı parametreleri değerlendirilmiştir. Yapılan bu çalışmada disleksi tanısı almış bireylerin, kontrol grubuna göre hem görsel algı becerileri performansının hem de okuma becerileri performansının azalmış olduğu sonucuna ulaşılmıştır (Jones ve ark., 2008). Çalışmamızda da Olgu 1 ve Olgu 2 profillerinde, uygulanan kişi merkezli müdahale sonucu görsel algı becerilerindeki performanslarda puan artışı gözlenirken, yapılan okuma becerisi değerlendirmesiyle de akıcı okuma becerileri ve okuduğunu anlama becerileri performansına olumlu etki ettiği tespit edilmiştir.

Çalışmamızda 9 yaşında olan Olgu 2 profilinde hem görsel algı becerileri performansında hem de okuma becerileri performans puanındaki artışın 14 yaşında olan Olgu 1'e oranla belirgin bir 
Tablo 4: Olgu 2'nin 1. ve 2. Değerlendirme Sonuçları

\begin{tabular}{|c|c|c|}
\hline OLGU: B.E & 1. Değerlendirme & 2.Değerlendirme \\
\hline Motor-Free Vısual Perceptın Test ; & & $8 / 8$ \\
\hline 1-Görsel Hafıza(1) & $8 / 8$ & $12 / 13$ \\
\hline 2-Görsel Tamamlama(1) & $10 / 13$ & $10 / 11$ \\
\hline 3-Görsel Ayrım & $7 / 11$ & $5 / 5$ \\
\hline 4-Görsel Uzaysal İlişki & $0 / 5$ & $3 / 5$ \\
\hline 5-Şekil-Zemin Algısı & $1 / 5$ & $3 / 5$ \\
\hline 6-Görsel Tamamlama(2) & $3 / 5$ & $3 / 5$ \\
\hline 7-Görsel Hafıza(2) & $3 / 5$ & 38 \\
\hline $\begin{array}{c}\text { Sesli Okuma Becerisi ve } \\
\text { Okuduğunu Anlama Testi-2; }\end{array}$ & & 53 \\
\hline 1-Okuma Hızı Puanı & 24 & 111 \\
\hline 2-Doğru Okuma Puanı & 38 & 54 \\
\hline 3-Akıcı Okuma Puanı & 106 & \\
\hline 4-Okuduğunu Anlama Puanı & 51 & \\
\hline
\end{tabular}

şekilde yüksek olduğu tespit edilmiştir. Bu durumun sebebi olarak ise aralarındaki yaş farkının, dolayısıyla da erken müdahalenin disleksi tanılı çocuklarda daha etkin olabileceği düşünülmüştür. Aslan tarafından 2015 yılında yapılan çalışmada da özgül öğrenme güçlüğünün erken dönem belirtilerinin tanımlanması ve bireyin erken müdahale programları ve gerekli sağlık ve eğitim hizmetlerine yönlendirilmesinin, böylece sağlanan erken müdahale ile bireylerin akademik, psikolojik, sosyal ve duygusal alanlarda yaşanılan problemleri en aza indirebileceği belirtilmiştir (Aslan,2015). Doğan da çalışmasında erken tanı ve müdahalenin, öğrenme güçlüğü olan çocukların genel gelişimsel düzeylerinin artmasına ve ileriki yıllarda da gerekli akademik beceriler için sağlam bir temel oluşturulmasına yardım ettiğini vurgulamaktadır (Doğan, 2012).

Bu çalışmanın klinik ortamda yapılmış olması sebebiyle, çocuklardan üçü ulaşım problemi yaşayarak tedaviyi tamamen bırakmışlardır. Çalışma- nın birlikte tamamlandığı iki çocukla ise okul saatleri sebebiyle müdahale programına uygunluk konusunda problem yaşanmıştır. Karşılaşılan diğer bir zorluk ise ailelerin disleksi konusunda bilinç ve farkındalık düzeylerinin düşük olması sebebiyle müdahale programlarının aksakığa uğramasıdır.

Sonuç olarak bu çalışmada; disleksi tanısı almış çocuklarda kişi merkezli ergoterapi müdahalesi kapsamında uygulanan görsel algı becerilerini geliştirmeye yönelik müdahalenin, okuma becerilerine olumlu etki ettiği tespit edilmiştir. Bu çalışma göz önünde bulundurularak konuyla ilgili yapılacak olan çalışmaların daha fazla örneklemin yer aldığı geniş katııımlı gruplarla, daha uzun süreli uygulanması şeklinde planlanmasıyıa, bunun yanı sıra aile bireyleri ve eğitimcilerin disleksi tanısı almış çocukların yaşayabilecekleri problemler ve intiyaçları olan müdahalelerin önemliliği hakkında bilgilendirilmesi, bu konuda farkındalık oluşturulması ile daha iyi sonuçlar elde edileceği düşünülmektedir. 


\section{KAYNAKLAR}

Arı, M. (1992). Öğrenme güçlüğü ve dikkat dağınıklığı. Ankara: Kök Yayıncılık.

Aslan, K. (2015). Özgül öğrenme güçlüğünün erken dönem belirtileri ve erken müdahale uygulamalarına dair derleme. Hacettepe University Faculty of Health Sciences Journal, 1.

Colarusso, R.P., \& Hammill, D.D. (2003). Motor-Free Visual Perception Test-Third Edition Manual. Academic Therapy Publications Novato, California

Cooke, D. M., McKenna, K., \& Fleming, J. (2005). Development of a standardized occupational therapy screening tool for visual perception in adults. Scandinavian Journal of Occupational Therapy, 12(2), 59-71.

Doğan, H. (2012). Özel öğrenme güçlüğü riski taşıyan 5-6 yaş çocukları için uygulanan erken müdahale eğitim programının etkisinin incelenmesi. Yayımlanmamış doktora tezi. Marmara Üniversitesi, İstanbul.

Jaklewicz, H. (1997). Twenty-five years of Iongitudinal studies on dyslexia. Document Resume, 151.

Jones, M. W., Branigan, H. P., \& Kelly, M. L. (2008). Visual deficits in developmental dyslexia: relationships between non-linguistic visual tasks and their contribution to components of reading. Dyslexia, 14(2), 95-115.

Grajo, L., Candler, C. (2014). Children with reading difficulties. How occupational therapy can help? Erişim tarihi: 5 Kasım 2016. https://www.aota. org/-/media/Corporate/Files/Practice/Children/ classroom-trouble-learning-to-read.pdf

Karatepe, G. (Haziran 2009). Disleksi ve tedavi yaklaşımı. Erişim tarihi: 12 Aralık 2016. http://www. tavsiyeediyorum.com/makale_3196.htm

McCane, S. J. (2006). Test review: Motor-free visual perception test. Journal of Psychoeducational Assessment, 24(3), 265-272.

Melekoğlu, M. A., Çakıroğlu, O., Erden, G., Kırbaş, F., Tunç, A., \& Teker, Ö. S. (2014). Özel öğrenme güçlüğü olan çocukların okuma becerilerini değerlendirmek için standart bir sesli okuma testi geliştirme projesi: Pilot araştırma sonuçları. 24. Ulusal Özel Eğitim Kongresinde sözlü bildiri, Edirne.

Özat, N. E. (2010). Öğrenme güçlüğü yaşayan çocuklarda Frostig Görsel Algı Eğitim Programının etkisi. Yayınlanmış yüksek lisans tezi, Abant İzzet Baysal Üniversitesi, Sosyal Bilimler Enstitüsü, Özel Eğitim Anabilim Dalı, Bolu.

Özkök-Kayhan, E. (2011). ilköğretim birinci kademe çocuklarında okuduğunu anlama ile sözcük bilgisi, görsel algı ve kısa süreli bellek arasındaki ilişki. Yayınlanmamış Yüksek Lisans Tezi. Ankara Üniversitesi Sosyal Bilimler Enstitüsü, Ankara.
Rodrigues, A. P., Rebola, J., Jorge, H., Ribeiro, M. J., Pereira, M., van Asselen, M., \& et.al. (2017). Visual perception and reading: New clues to patterns of dysfunction across multiple visual channels in developmental dyslexiavisual channels in dyslexia. Investigative Ophthalmology \& Visual Science, 58(1), 309-317.

Teleb, A., Mohamed, W., \& Elbert, T. (2016). Does enhancing visual perception in mild intellectually disabled children transfer to other skills?. In ICEEPSY 2016: International Conference on Education and Educational Conference. 